\title{
Analysis of the cross-correlation between seismicity and water level in the Aswan area (Egypt) from 1982 to 2010
}

\author{
L. Telesca ${ }^{1}$, R. ElShafey Fat ElBary ${ }^{2}$, A. El-Ela Amin Mohamed ${ }^{3}$, and M. ElGabry ${ }^{3}$ \\ ${ }^{1}$ Consiglio Nazionale delle Ricerche, Istituto di Metodologie per l'Analisi Ambientale, Tito, Italy \\ ${ }^{2}$ Aswan Earthquake Regional Research Center, Aswan, Egypt \\ ${ }^{3}$ National Research Institute of Astronomy and Geophysics, Helwan, Cairo, Egypt
}

Correspondence to: L. Telesca (luciano.telesca@imaa.cnr.it)

Received: 11 April 2012 - Accepted: 17 May 2012 - Published: 12 July 2012

\begin{abstract}
In this study the correlation between the monthly fluctuations of the water level of the Aswan High Dam and monthly number of earthquakes from 1982 to 2010, which occurred in the surrounding area, was investigated. Our findings reveal that significant correlation is present during the period 1982-1993 between water level and shallow seismicity (depth less than $15 \mathrm{~km}$ ). The deep seismicity (depth larger than $15 \mathrm{~km}$ ) is significantly correlated with the water level between January and April 1989. The time lag of the significant maximal cross-correlation varies from 2-8 months for the shallow seismicity, while it is around 7-8 months for the deep seismicity. These values of the time lags could be in favour of the presence of two distinct triggering mechanisms: one due to pore pressure diffusion and the other due to fracture compaction (undrained response).
\end{abstract}

\section{Introduction}

The Aswan Dam was built about $13 \mathrm{~km}$ south of Aswan city (Egypt). It rises $111 \mathrm{~m}$ above the Nile River base, impounding one of the largest artificial freshwater lakes in the world. The 1981 Aswan earthquake occurred $17 \mathrm{yr}$ after the reservoir filling. The mainshock and many aftershocks occurred at depths between 15 to $25 \mathrm{~km}$ beneath the northwestern edge of the reservoir. The delay from the start of filling to the onset of seismicity and the depth of the hypocenters raise questions about the nature of reservoir-induced seismicity in the Aswan area.

The seismicity at Aswan is confined mainly to the Wadi Kalabsha area (Fig. 1), whose topography is controlled by the Kalabsha fault. From 1975 to 1985, the areal extent of the reservoir in the Kalabsha region changed significantly. The region first flooded in 1975. Although the water level rose and fell about the $174 \mathrm{~m}$ level during annual cycles from 1975 to 1982 , the area presumably remained wet until after the 1982-1983 peak in water level. Since then, the water level has remained below the elevation of $174 \mathrm{~m}$.

Because of the significant changes in the areal extent of the reservoir and in the water table, the water level at Aswan is not a direct measure of the forcing function for the induced seismicity, as it may be at other reservoirs (Simpson et al., 1989). The Aswan reservoir cannot be approximated by a point or line source like many other reservoirs; and the water depth in the reservoir, as measured at the dam, cannot represent the temporal variation in the surface load. A more complete description of the temporal and spatial variation in the load of the reservoir would require a complete modelling of the reservoir-groundwater interaction and the related large changes in the regional groundwater surface (Liu et al., 2011; do Nascimento et al., 2005). However, this challenging question will not be investigated in the present study, which deals with the relationship between the reservoir water level and seismicity in Aswan. Such a relationship was investigated in several studies. Awad and Mizoue (1995) found that the temporal variations of shallow seismic activity were associated with a high rate of water level fluctuation in Lake Aswan, while the correlation with the deeper earthquake sequence was not evident. This implied a discrimination between two different groups on the base of the hypocentral depth. Selim et al. (2002) studied the cross-correlation between the water level and the seismicity in the Aswan area from 1982 to 1998. They found that the highest maximal correlation coefficient at time lag of 2 months was obtained in the period 


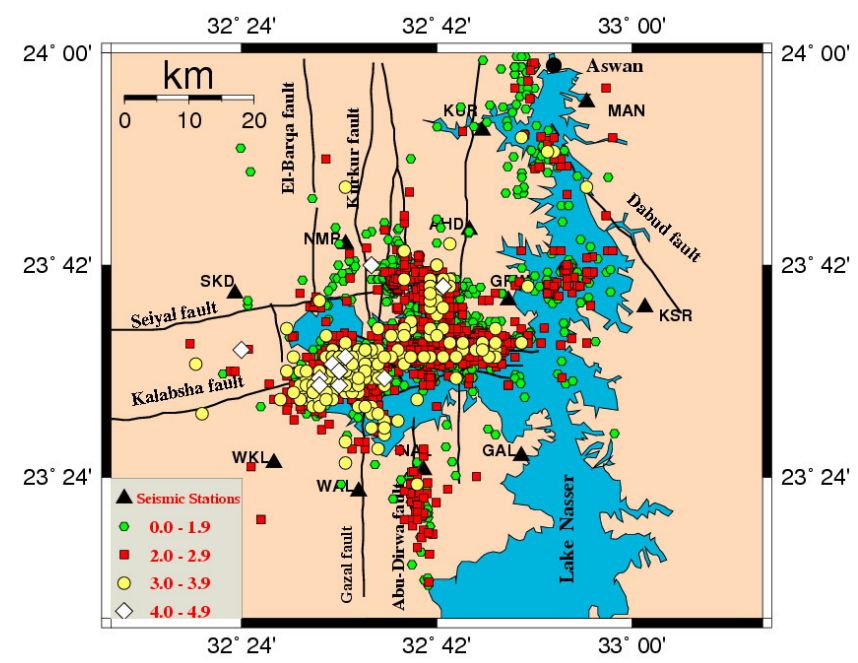

Fig. 1. Spatial distribution of the Aswan seismicity.

1982-1985, considering all the events with depth $h \leq 40 \mathrm{~km}$ and magnitude $M \geq 2.0$. In all the other periods, the crosscorrelation coefficient was very small, leading to a generally weak relationship between the water fluctuations and seismicity. Mekkawi et al. (2004) studied the 1982-2001 shallow (between 0 and $15 \mathrm{~km}$ ) and deep (between 15 and $30 \mathrm{~km}$ ) Aswan seismicity, finding that among all the possible seismic parameters, only the seismicity rate correlates with the seasonal fluctuations of the lake level, indicating positive evidence for the Aswan seismicity to be reservoir-triggered in the 1982-2001 period. Furthermore, time and space clusterization indicated that numerous aftershocks are activated, suggesting that the Aswan seismicity emerges both from the water level loading and the interplay between induced earthquakes themselves through the aftershock activation. However, in their analysis, it was argued that the dominating presence of aftershocks induces stochastic fluctuations in the seismicity rate that hide the simple seismic response to water level changes.

\section{Seismicity data}

In this study, the earthquake catalog of Aswan area from 1 January 1982 to 31 December 2010 is used. The data were extracted from Bulletins of the Aswan Earthquake Regional Research Center. The focal depth $h$ is less than $40 \mathrm{~km}$ and distributed like a double-humped function (Fig. 2), with a minimum around $15 \mathrm{~km}$. The total number of the events, whose magnitude range from -0.3 to 5.9 , is 7901 . The depth error is less than $1.5 \mathrm{~km}$ (El-Hady, 2004).

We firstly declustered the seismic catalog to avoid bias due to the aftershocks of the strongest events, using the Reasenberg (1985) algorithm and obtaining a declustered sequence of 3545 events, whose monthly counts are shown in Fig. 3. Since 2005 the monthly event number significantly increased

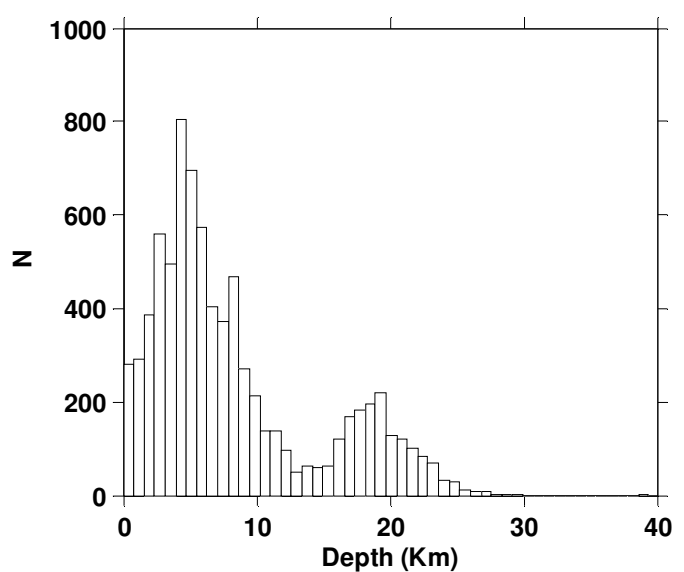

Fig. 2. Depth distribution of the whole seismicity.

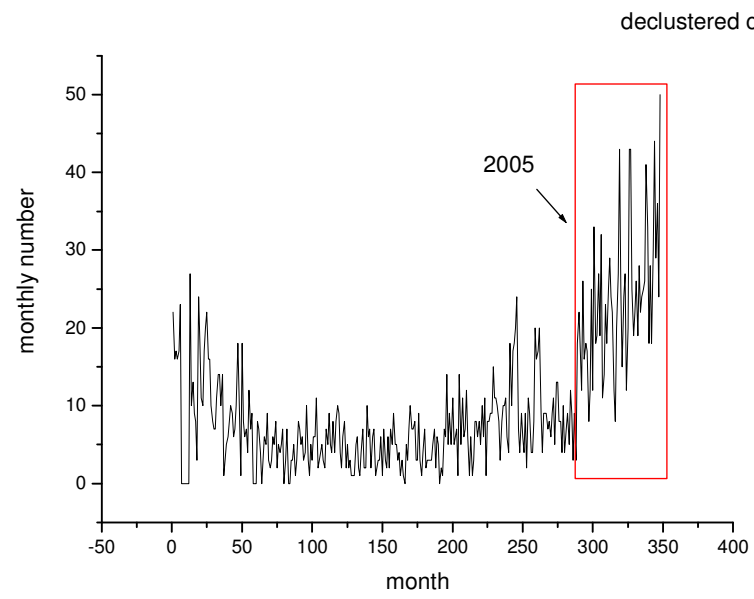

Fig. 3. Monthly seismic activity of the declustered catalogue (all the magnitudes).

due to the analog to digital change of acquisition system. In order to deal with this apparent temporal inhomogeneity (Habermann, 1987), we analysed the time variation of the completeness magnitude $M_{\mathrm{c}}$, defined as the magnitude at which a power law can model $90 \%$ or more of the frequencymagnitude distribution (Wiemer and Wyss, 2000) (Fig. 4), and we can conclude that all earthquakes with $M \geq 2.5$ are exactly recorded during the observation period. The b-value varies between about 0.8 and 1.2 (not shown); such relatively small variation could indicate absence of man-made effects (Katsumata, 2011). Thus, the declustered Aswan catalog can be considered temporally homogeneous between 1982 and 2010 for events with magnitude $M \geq 2.5$, which will be assumed as threshold magnitude hereafter. 


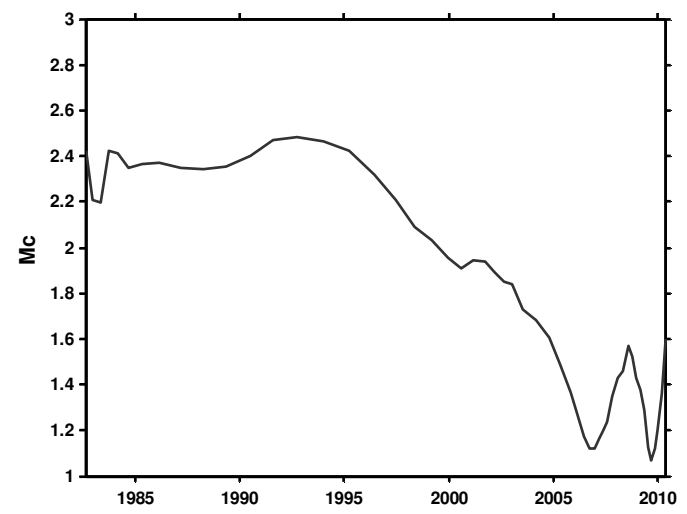

Fig. 4. Time variation of the completeness magnitude for the declustered catalogue.
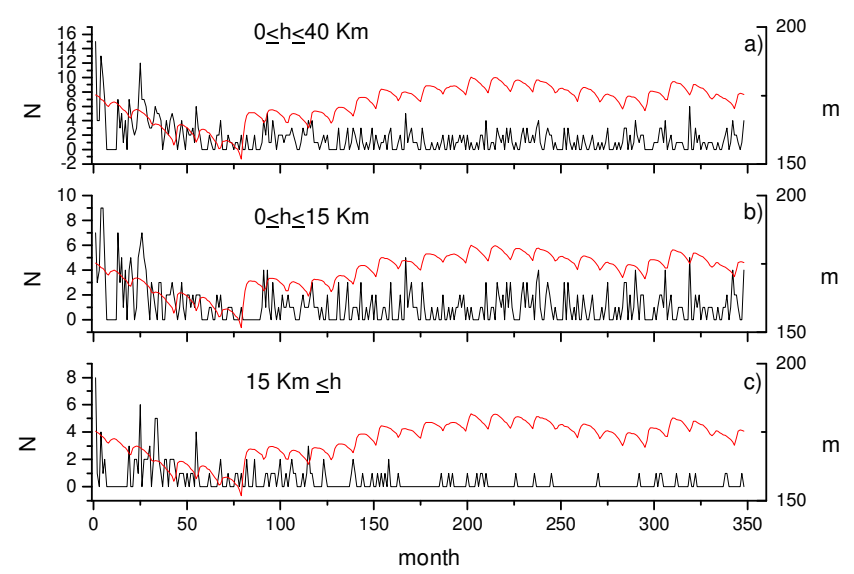

Fig. 5. Monthly maximum water level and number of earthquakes with $M \geq 2.5$ for the whole (a), shallow (b) and deep (c) seismicity.

\section{Data analysis}

On the base of the depth distribution of the seismicity (Fig. 2), the cross-correlation with the water level was performed for two depth ranges: $h \leq 15 \mathrm{~km}$ (shallow) and $15 \mathrm{~km}<h \leq 40 \mathrm{~km}$ (deep). Figure 5 shows the monthly variation of the maximum water level and the number of events with $M \geq 2.5$ for any focal depth (Fig. 5a), for shallow (Fig. 5b) and for deep events (Fig. 5c). Figure 6 shows the cross-correlation between water level and monthly counts and the $99 \%$ confidence curve, calculated as in Telesca (2010). Based on the Fourier transform method, surrogates of the first series are obtained, starting with a randomized shuffle. Shuffling destroys the original dynamical structure (like correlations) in a series. Then, the desired spectral amplitudes from the original series are imposed in order to force the same cyclic autocorrelation (Little et al., 2006). After generating 1000 surrogates, the crosscorrelation of each surrogate with the second series is calculated. The range of values that contain at least $99 \%$ of

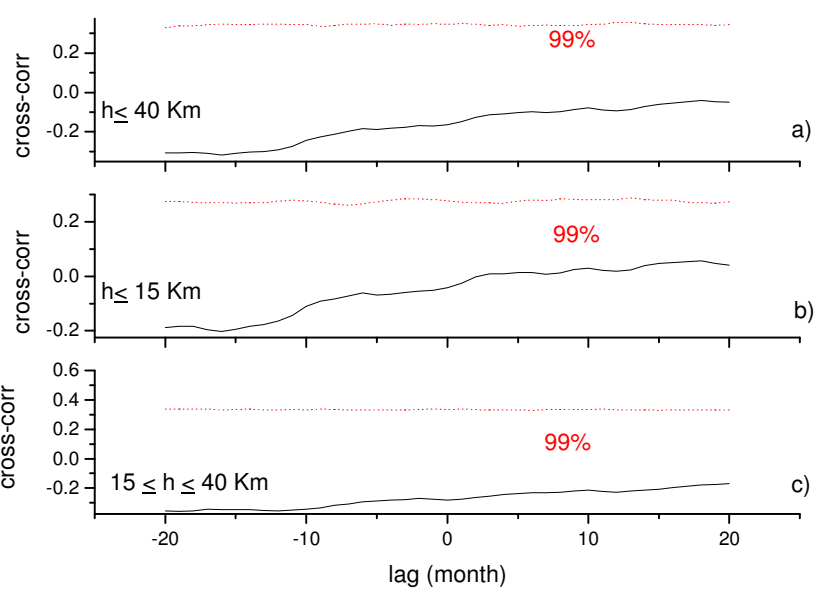

Fig. 6. Cross-correlation between water level and number of earthquakes for the whole (a), shallow (b) and deep (c) seismicity. The red dotted lines are the $99 \%$ confidence curves.

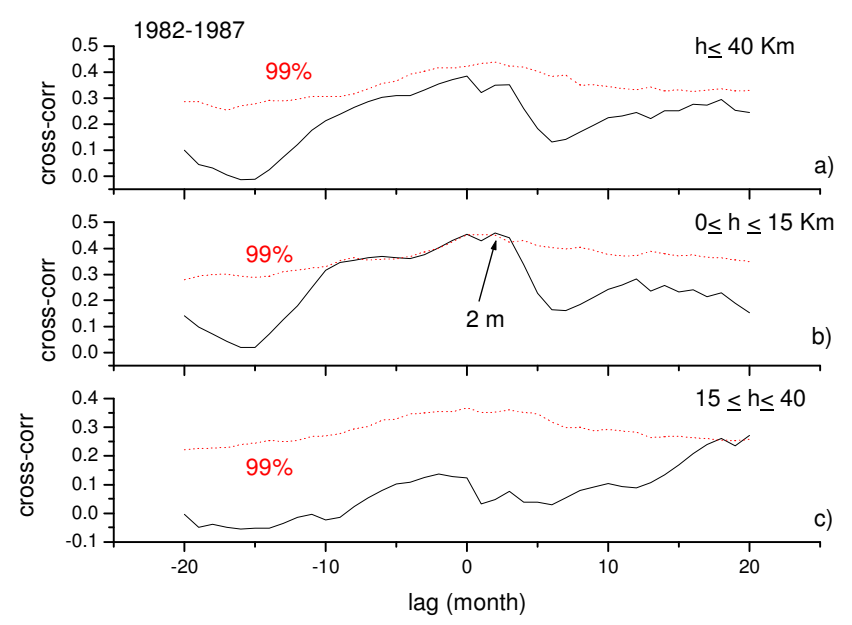

Fig. 7. Cross-correlation between water level and number of earthquakes for the whole (a), shallow (b) and deep (c) seismicity in the period 1982-1987. The red dotted lines are the $99 \%$ confidence curves.

the cross-correlation coefficients for a given time lag is the $99 \%$ confidence interval for that time lag. Figure 6 indicates that no significant correlation exists between water level and monthly seismic activity in relation with the whole observation period. Figure 7 shows the cross-correlation between the water level and the monthly counts, considering all the events (Fig. 7a), only shallow ones (Fig. 7b), and only deep ones (Fig. 7c) during the period 1982-1987. The maximal cross-correlation is significant only for shallow events with value of $\sim 0.46$ at time lag of 2 months. The analysis on the periods 1988-1993, 1994-1999, 2000-2004 and 20052010 was performed only for the shallow seismicity, because the number of deep events with $M \geq 2.5$ in the same periods are not sufficient for a reliable statistical analysis. The 


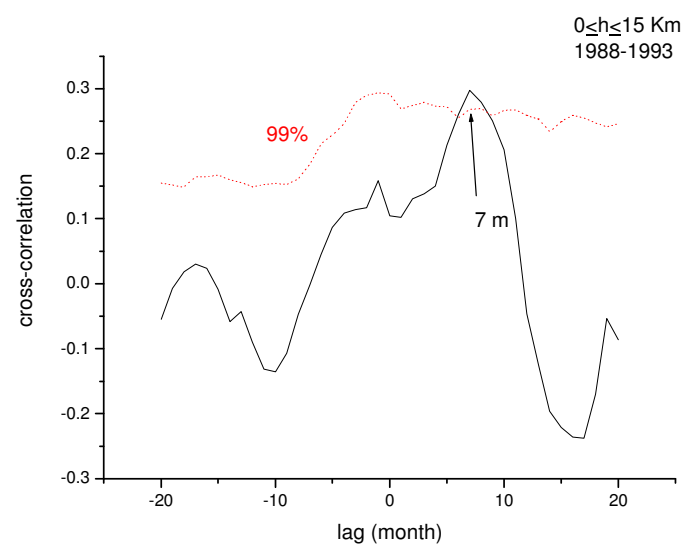

Fig. 8. Cross-correlation between water level and number of earthquakes for the shallow seismicity in the period 1988-1993. The red dotted lines are the $99 \%$ confidence curves.

cross-correlation is significant only during 1988-1993 with maximum $\sim 0.3$ at time lag of 7 months (Fig. 8). In order to investigate more finely the cross-correlation between water level and seismicity, we considered a time window of six years moving through the data, with a shift of one month. In each time window we calculated the following: (i) the maximal cross-correlation between water level and monthly event counts, (ii) its $99 \%$ confidence value, (iii) the corresponding time lag and (iv) the number of seismic events occurring in that time window. Each calculated value was associated with the time of the last datum of the time window. We considered only the values obtained in time windows with at least 50 events. Concerning the deep seismicity, the analysis was performed up to month 105 (starting from January 1982) (the red box in Fig. 9a); the water level is significantly correlated with the seismicity with maximum $\sim 4.5$ and time lag $\sim 8-9$ months, between the months 84 and 88 . Concerning the shallow seismicity, there are phases of significant crosscorrelation and others without (Fig. 9b). During the phases of significant cross-correlation, the positive time lags of the maximum are mostly concentrated in the first quarter of the whole period (up to the month 144) and change from 23 months to 7-9 months (Fig. 9c). Then, from the month 178 to the month 181, the time lag increases up to 11 months; at the months $244-245$, the time lag decreases down to 4 5 months; at the months 280-283, it decreases again down to 1 month. Such different values of the time lag can suggest a fracture compaction mechanism (time lags $\sim 1-3$ months) or a dominance of pore pressure triggering mechanisms (time lags $\sim 8-9$ months).

\section{Conclusions}

The cross-correlation between water level and seismicity in Aswan area was analysed. The cross-correlation analysis was performed by using the declustered seismic catalog, in order
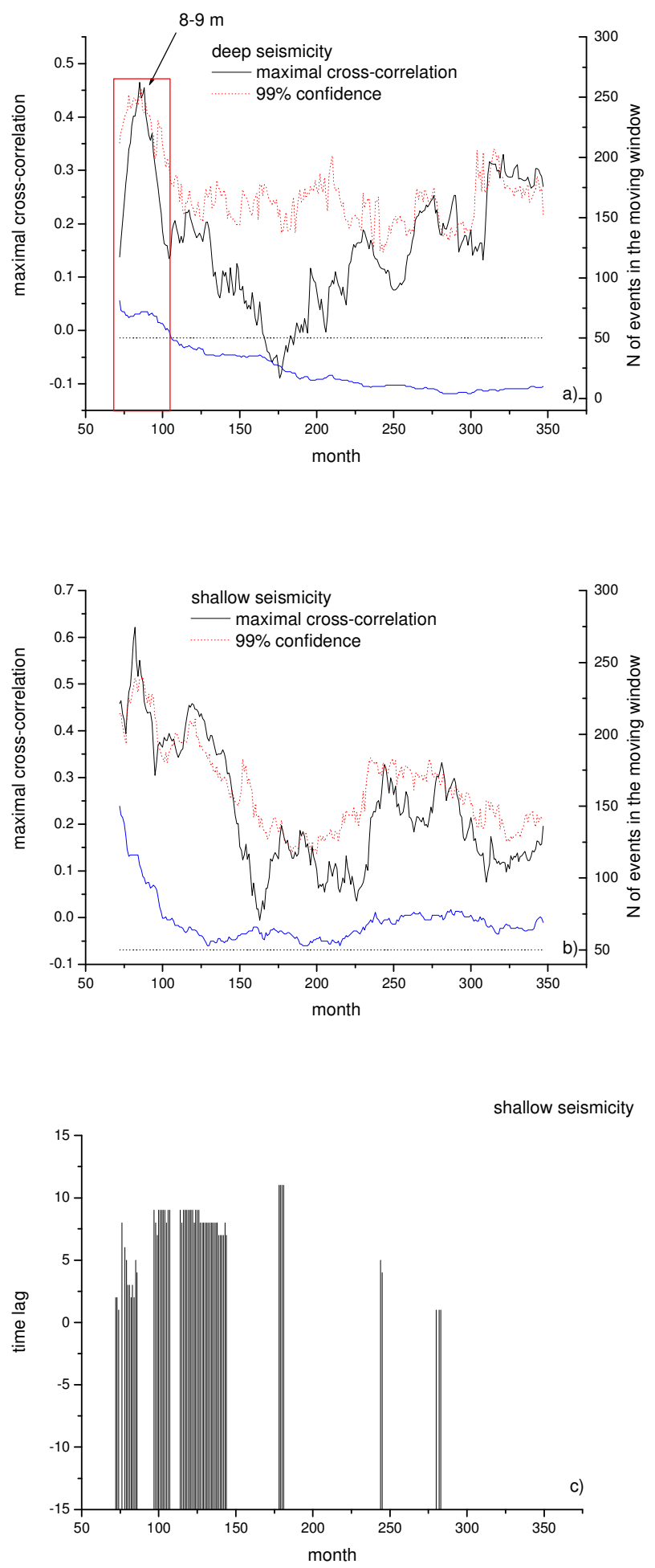

Fig. 9. Maximal cross-correlation coefficient (black) and $99 \%$ confidence curve (dotted red) for the deep (a) and shallow (b) seismicity. The blue curve represents the number of events in each moving window. (c) Time lag corresponding to the $99 \%$ significant maximal cross-correlation coefficient for the shallow seismicity. 
to avoid bias due to the presence of possible aftershocks. We investigated two depth ranges: shallow and deep. The cross-correlation with the water level of the deep seismicity is significant only for few months during the first $5 \mathrm{yr}$ of the investigated seismic record, while that of the shallow seismicity is significant in several time periods throughout the whole seismic record. This would suggest that the deep seismicity might be induced by the reservoir only within the few years after the impoundment of the dam, while the shallow seismicity seems to have a causal relationship with the reservoir operations more or less continuously throughout time. Two different earthquake triggering mechanisms of reservoir-induced seismicity could be identified: one due to pore pressure diffusion and the other due to fracture compaction (undrained response). Of course, the exact discrimination between the two triggering mechanisms needs further and deeper investigation, as well as the calculation of the hydraulic diffusivity coefficient. In the present study, we analysed the whole seismicity occurred in the Aswan area. In the future, it would be necessary to investigate the correlation between water level and seismicity for particular seismic zones, and derive for these suited hydrological models.

Acknowledgements. The present study was supported by the CNR/ASRT 2011-2012 Project "Spatiotemporal seismicity patterns and earthquake precursors at Aswan, Egypt. Contribution to earthquake hazard assessment".

Edited by: M. E. Contadakis

Reviewed by: A. do Nascimento and another anonymous referee

\section{References}

Awad, M. and Mizoue, M.: Earthquake Activity in the Aswan Region, Egypt, Pure Appl. Geophys., 145, 69-86, 1995.

do Nascimento, A. F., Lunn, R. J., and Cowie, P. A.: Numerical modelling of pore-pressure diffusion in a reservoir-induced seismicity site in northeast Brazil, Geophys. J. Int., 160, 249-262, 2005.

El-Hady, S. M.: Contribution of crustal rheology instability for earthquake eactivity around Nasser Lake, Egypt, J. Appl. Geophys., 4, 43-62, 2004.

Habermann, R. E.: Man-made changes of seismicity rates, Bull. Seismol. Soc. Am., 77, 141-159, 1987.

Katsumata, K.: A long-term seismic quiescence started 23 years before the 2011 off the Pacific coast of Tohoku Earthquake ( $\mathrm{M}=$ 9.0), Earth Planet. Space, 63, 709-712, 2011.

Little, M. A., McSharry, P. E., Moroz, I. M., and Roberts, S. J.: Testing the assumptions of linear prediction analysis in normal vowels, J. Acoust. Soc. Am., 119, 546-558, 2006.

Liu, S., Xu, L., and Talwani, P.: Reservoir-induced seismicity in the Danjiangkou Reservoir: a quantitative analysis, Geophys. J. Int., 185, 514-528, 2011.

Mekkawi, M., Grasso, J.-R., and Schnegg, P.-A.: A Long-Lasting Relaxation of Seismicity at Aswan Reservoir, Egypt, 1982-2001, Bull. Seismol. Soc. Am., 94, 479-492, 2004.

Reasenberg, P.: Second-order moment of central California seismicity, 1969-1982, J. Geophys. Res., 90, 5479-5495, 1985.

Selim, M. M., Imoto, M., and Hurukawa, N.: Statistical investigation of reservoir-induced seismicity in Aswan area, Egypt, Earth Planet. Space, 54, 349-356, 2002.

Simpson, D. W., Gharib, A. A., and Kebeasy, R. M.: Induced seismicity and changes water Level at Aswan reservoir, Egypt, Gerlands Beiträge zur Geophysik, special Issue on Induced Seismicity, Part II, 1989.

Telesca, L.: Analysis of the cross-correlation between seismicity and water level in Koyna area (India), Bull. Seismol. Soc. Am., 100, 2317-2321, 2010.

Wiemer, S. and Wyss, M.: Minimum magnitude of complete reporting in earthquake catalogs: examples from Alaska, the Western United States, and Japan, Bull. Seism. Soc. Am., 90, 859-869, 2000 . 